\title{
Atomic-scale Structure and Stability of the Low-index Surfaces of Pyrochlore Oxides
}

\author{
Pratik P. Dholabhai ${ }^{*}$, Romain Perriot, and Blas P. Uberuaga \\ Materials Science and Technology Division \\ Los Alamos National Laboratory \\ Los Alamos, NM 87545
}

\section{Supporting information}

Figure S1. Surface layer structures of the as-built and minimized surfaces for the 22 structural variants considered in GTO. The as-built structures of the surface layer also provide a reference of how the surface models for the different terminations were constructed. Only surface layer ions are shown for clarity. For (111) surface, ions in the top three layers are shown. Notation for the particular surface model is given on the left and the respective surface energy after minimization is given on the right. In all cases, the view is normal to the surface layer. Purple, green and red spheres correspond to the $\mathrm{Gd}, \mathrm{Ti}$ and $\mathrm{O}$ ions respectively.

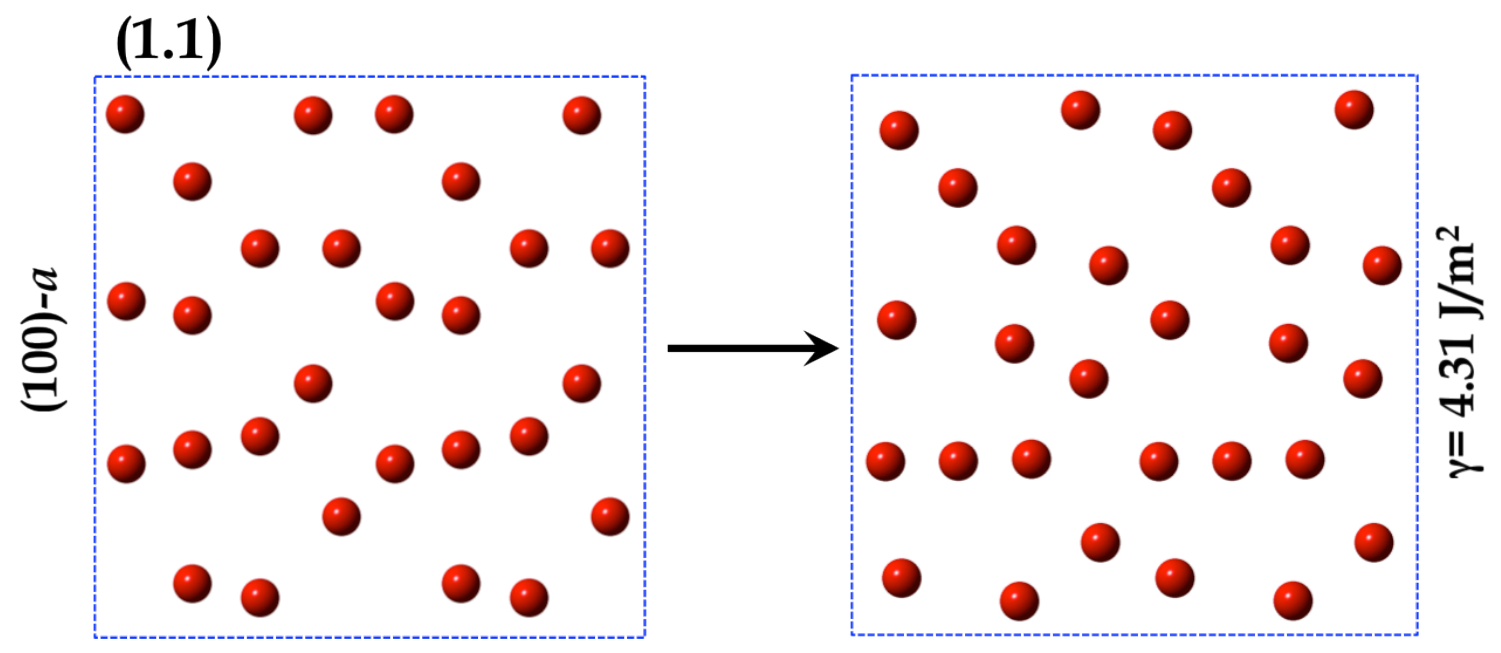




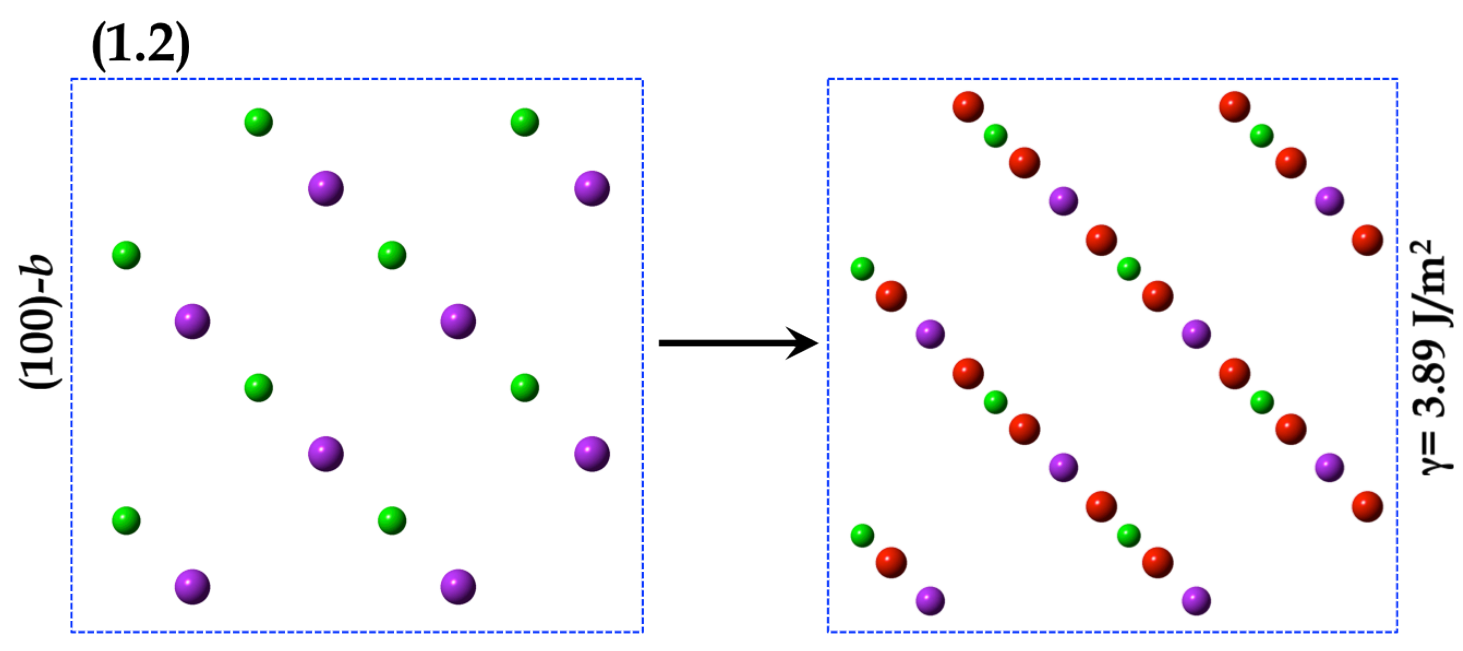

(1.3)

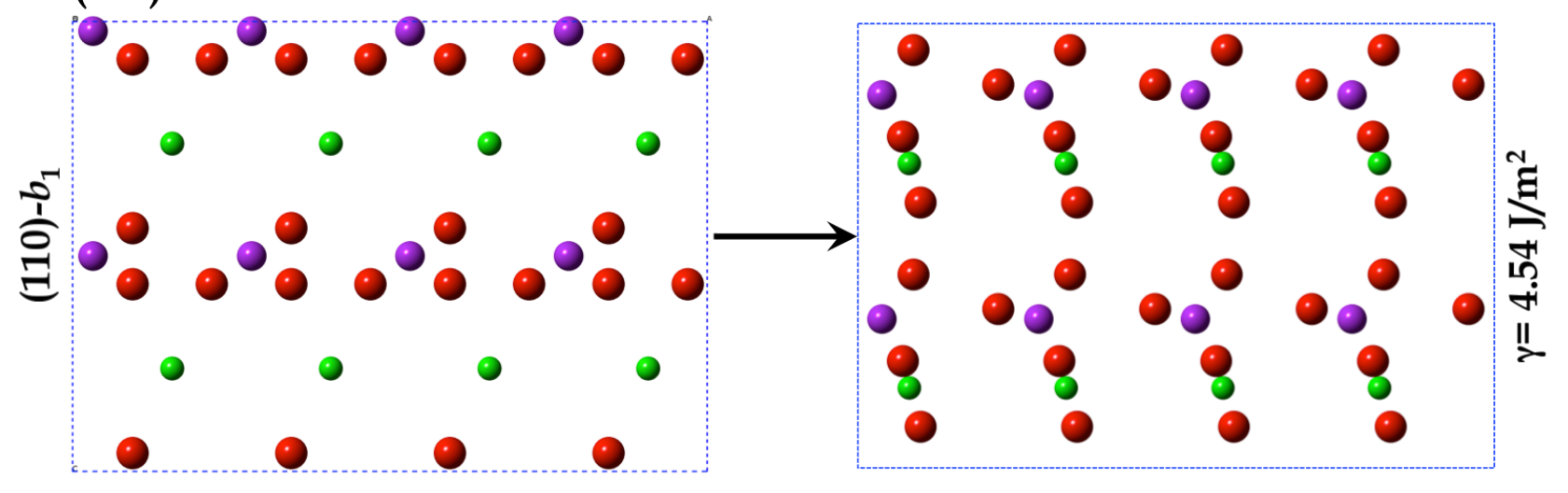

(1.4)

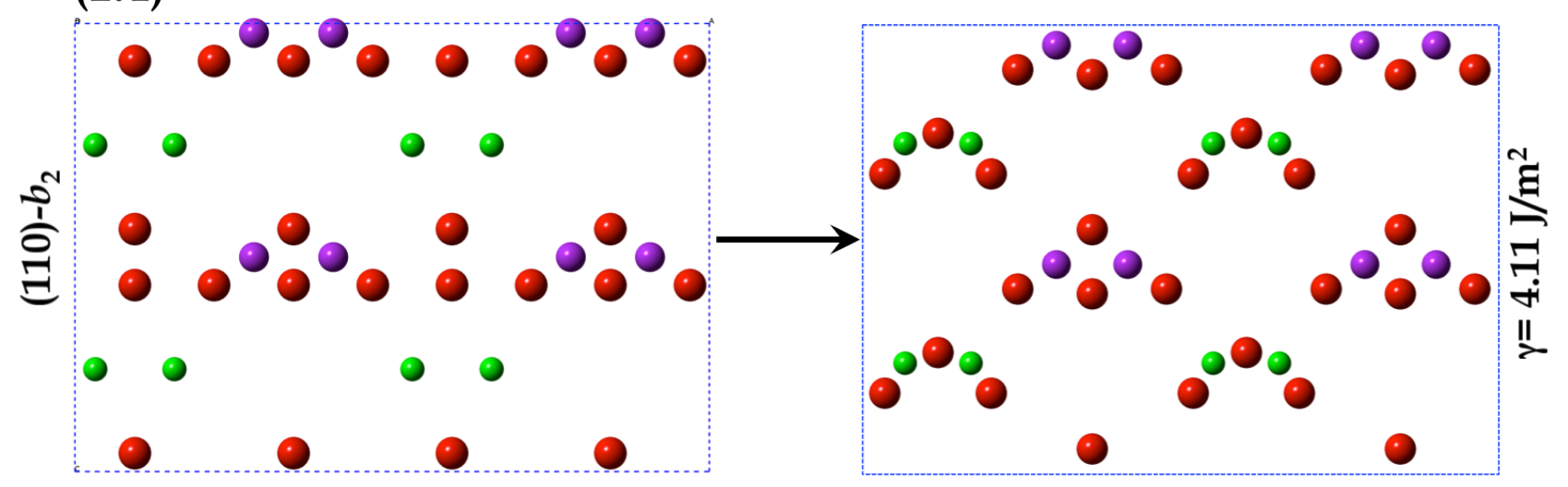


(1.5)

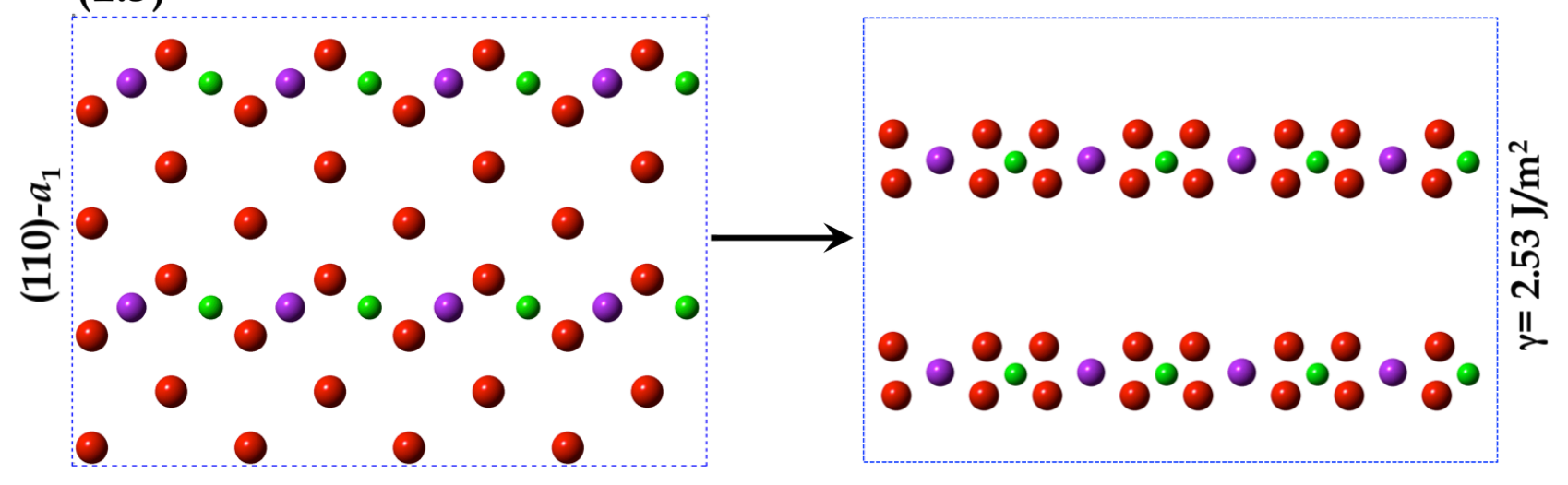

(1.6)
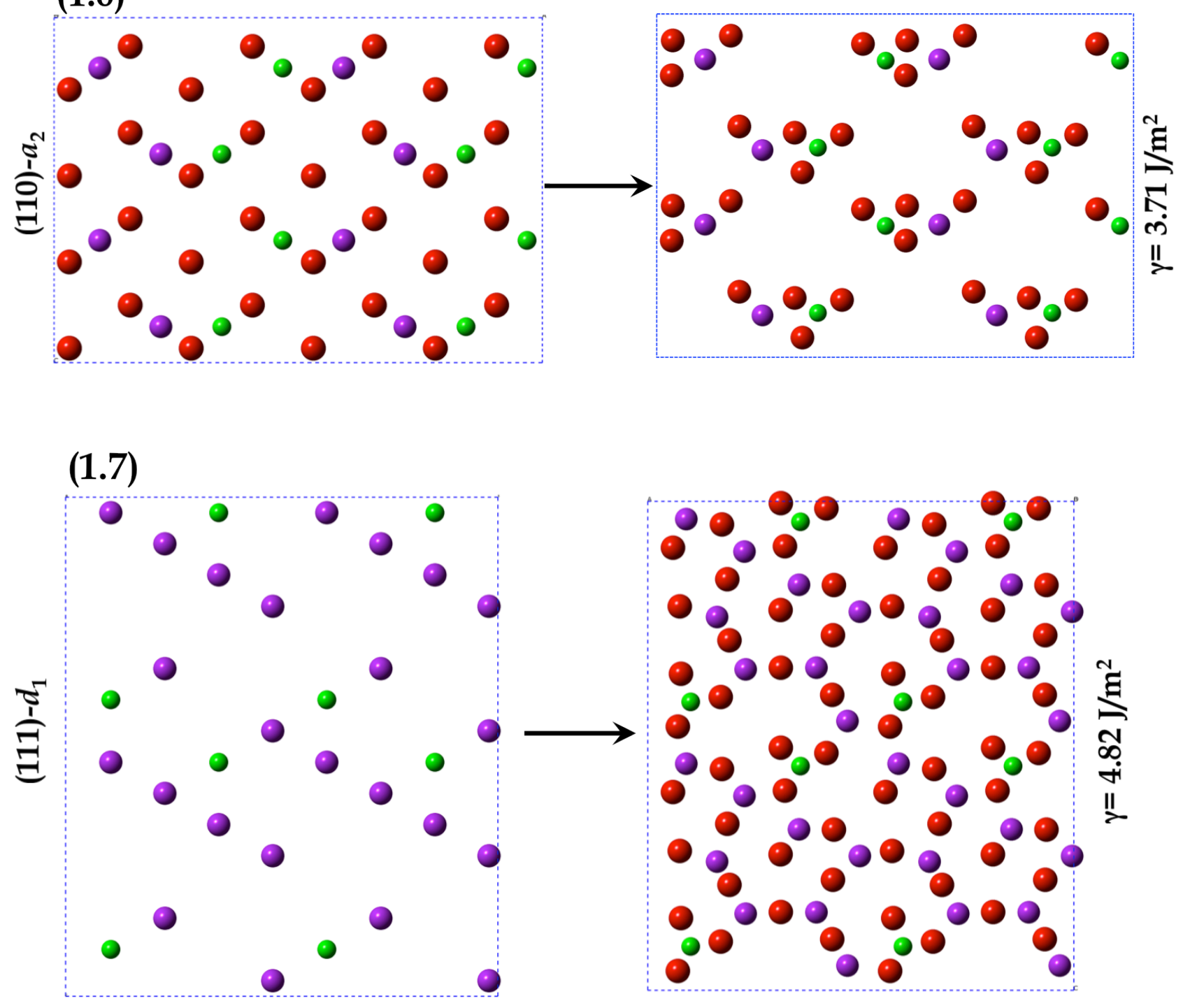

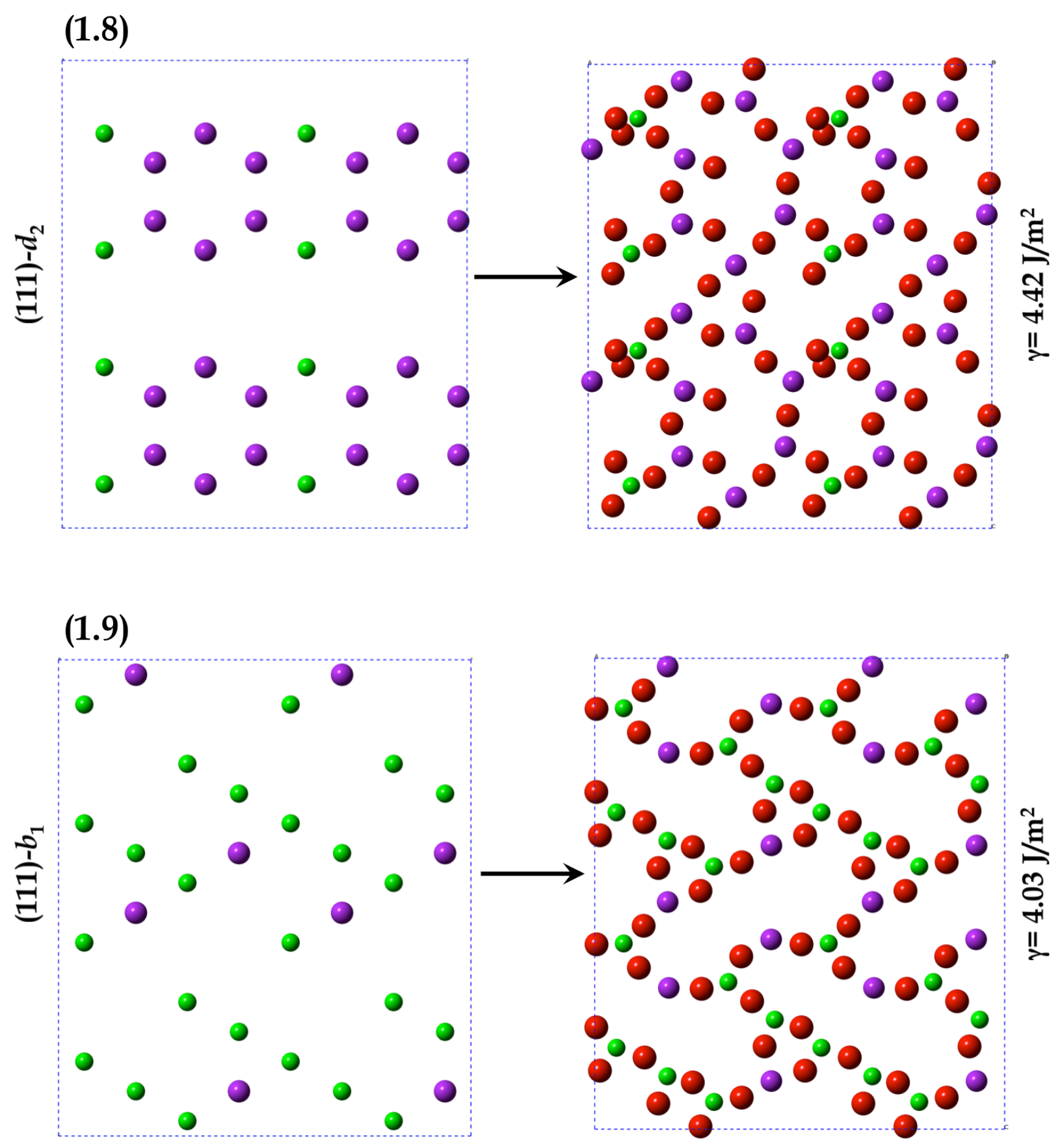

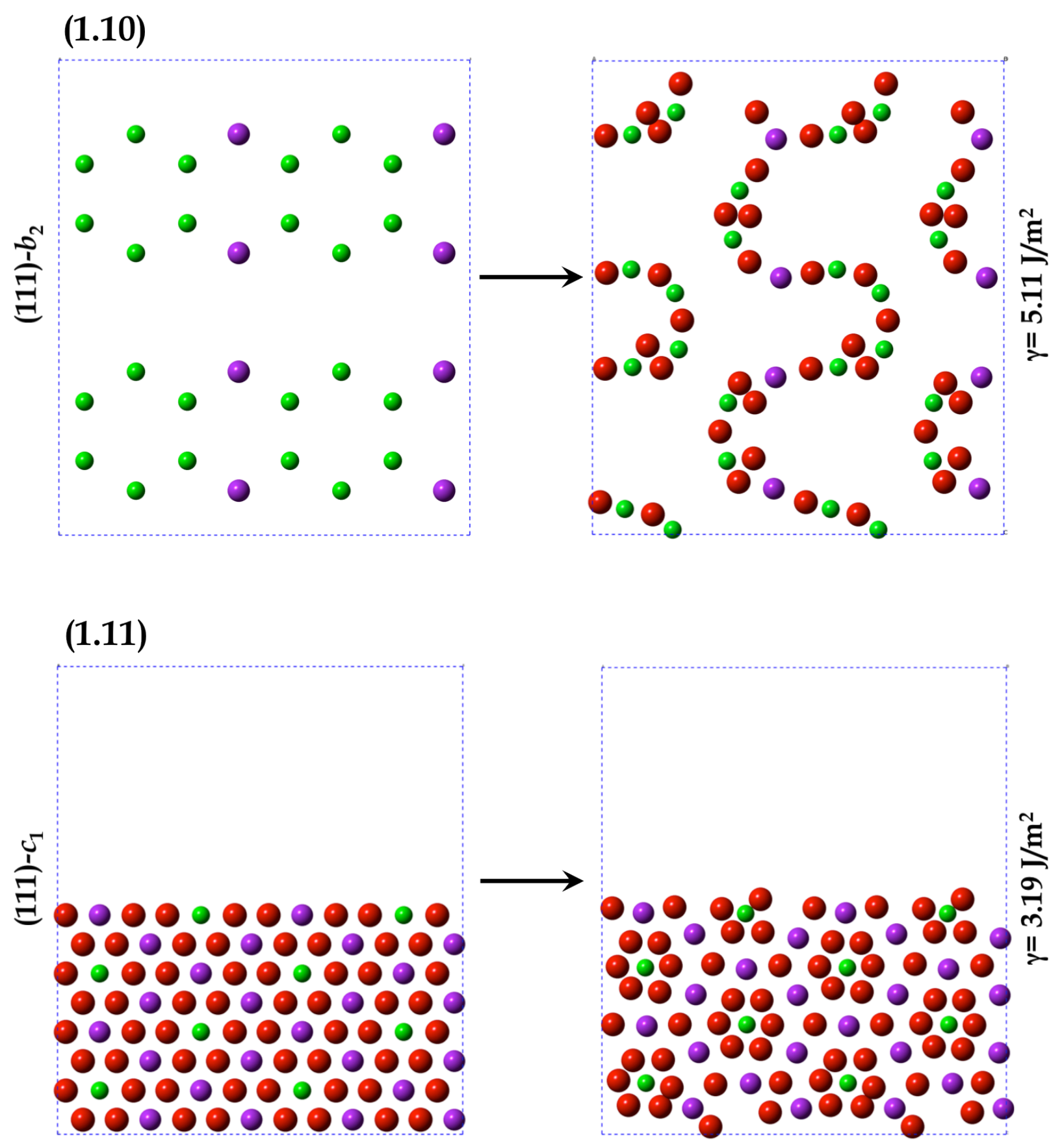


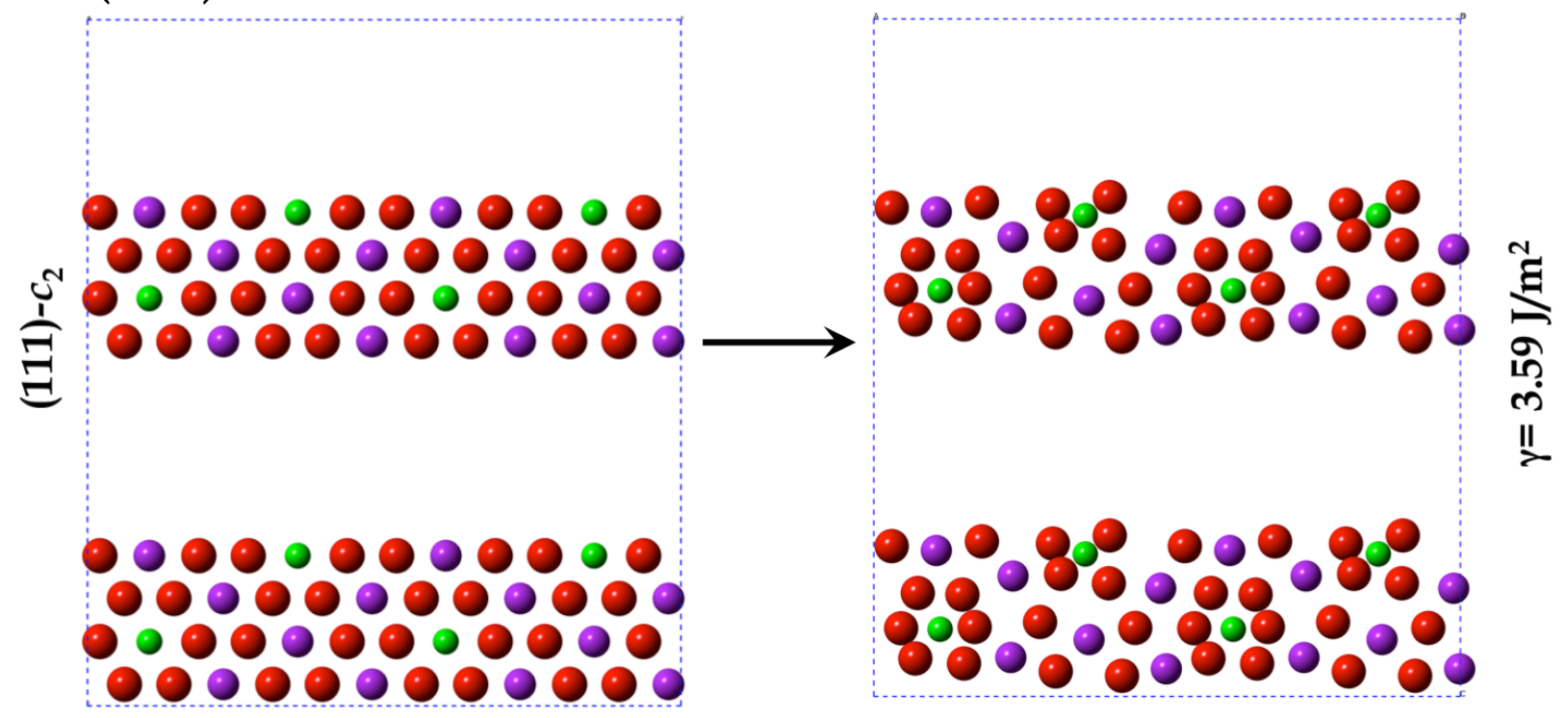

(1.13)

000000000000 000000000000

i

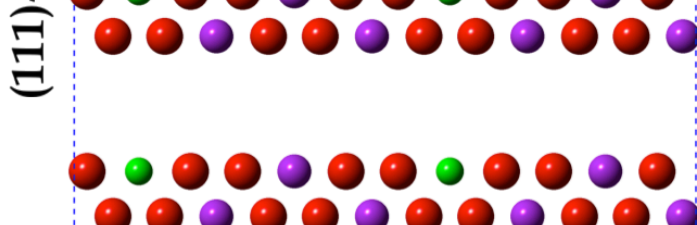
- O 000000000 - 000000000

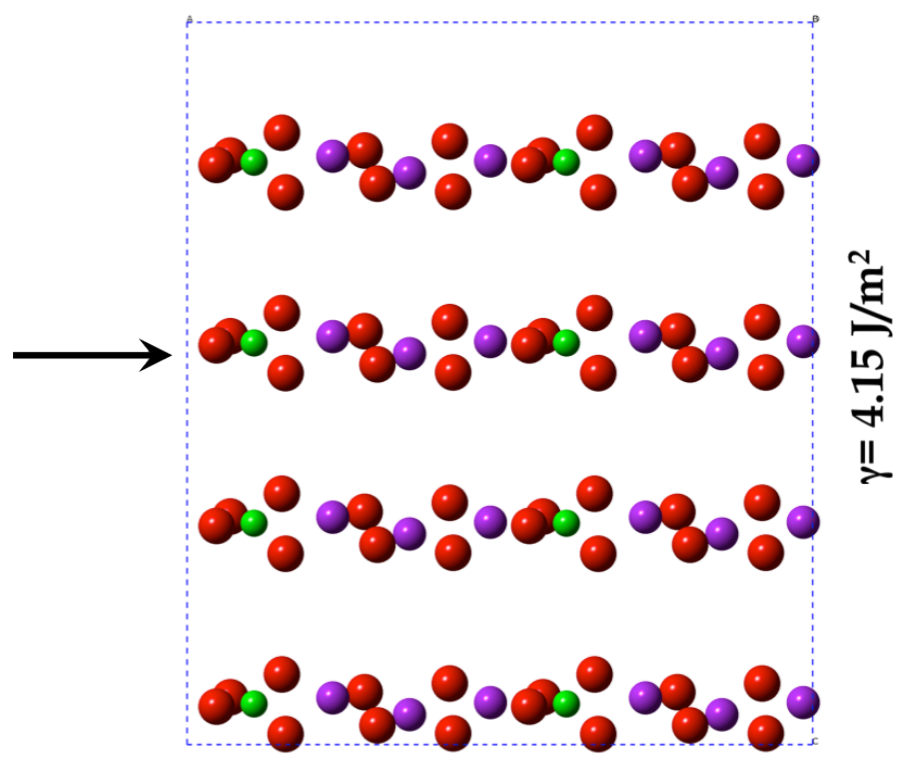




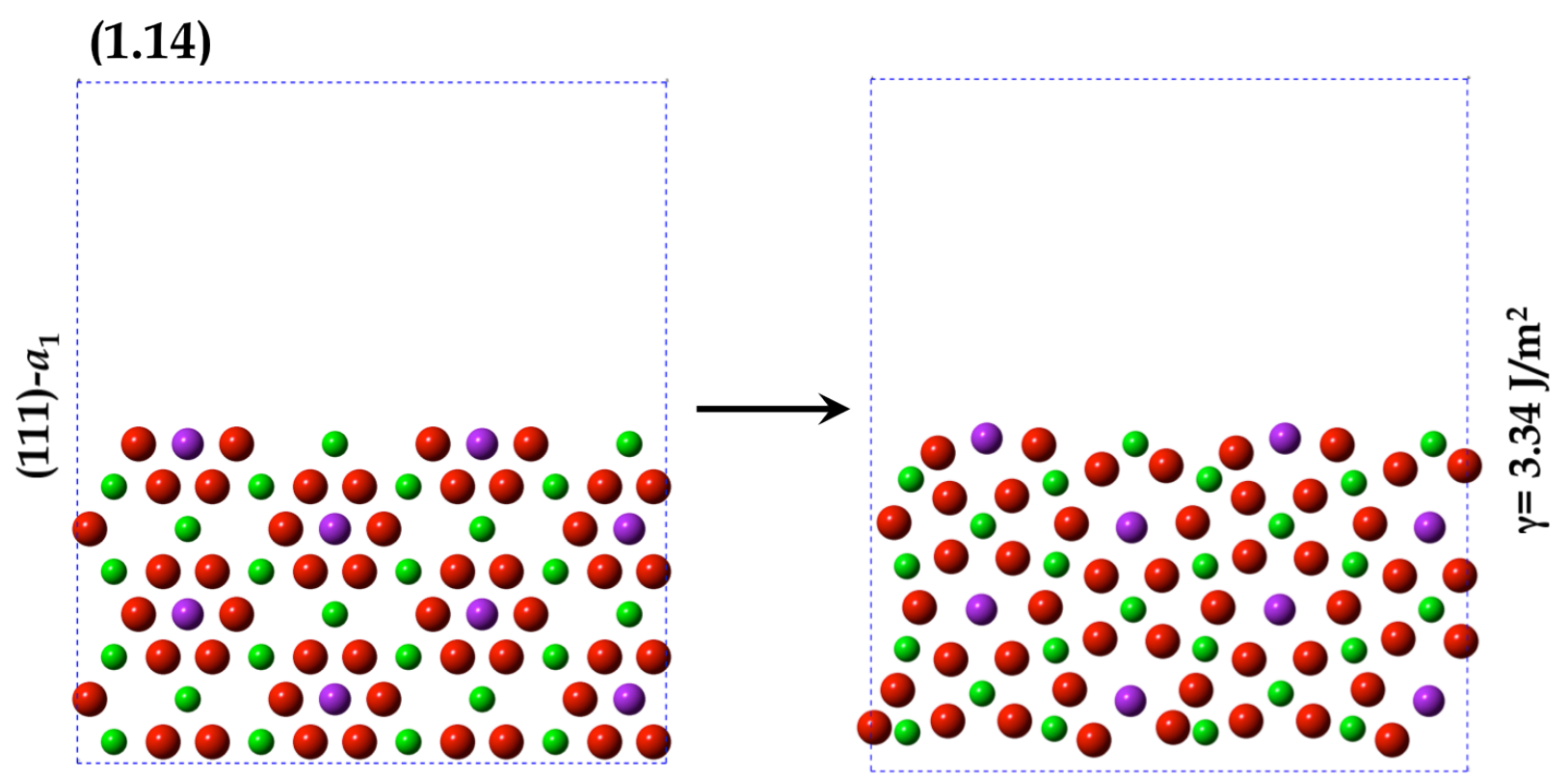

(1.15)

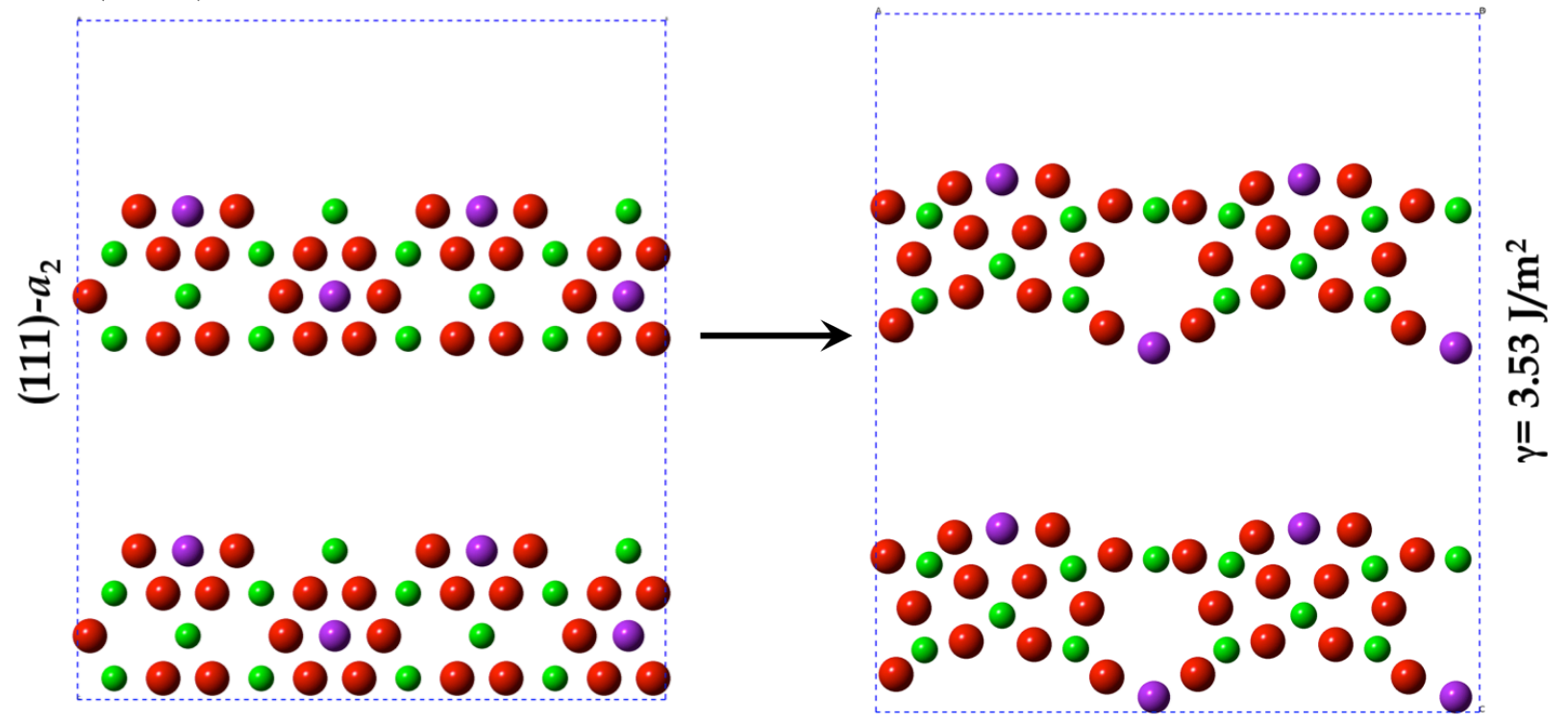


(1.16)

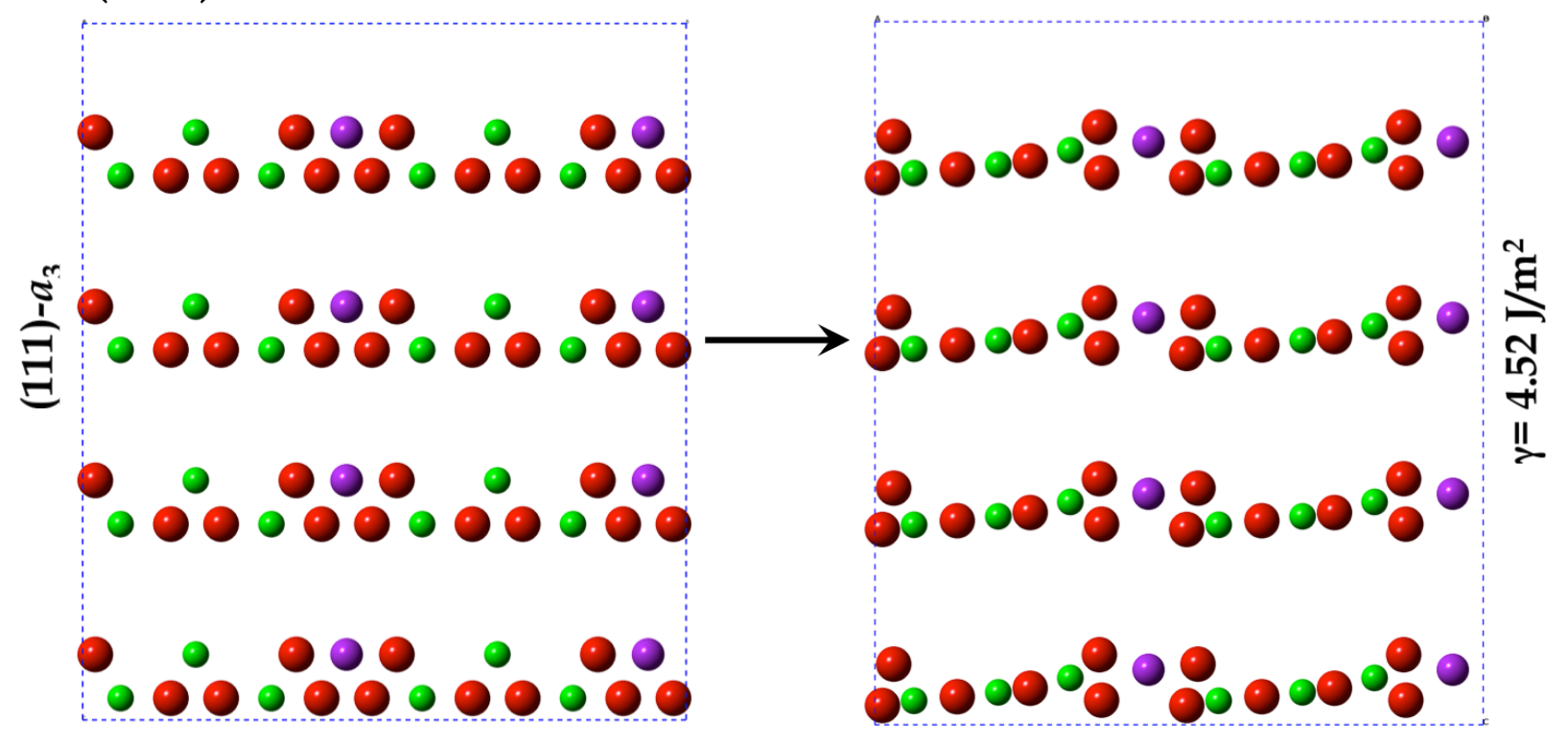

(1.17)

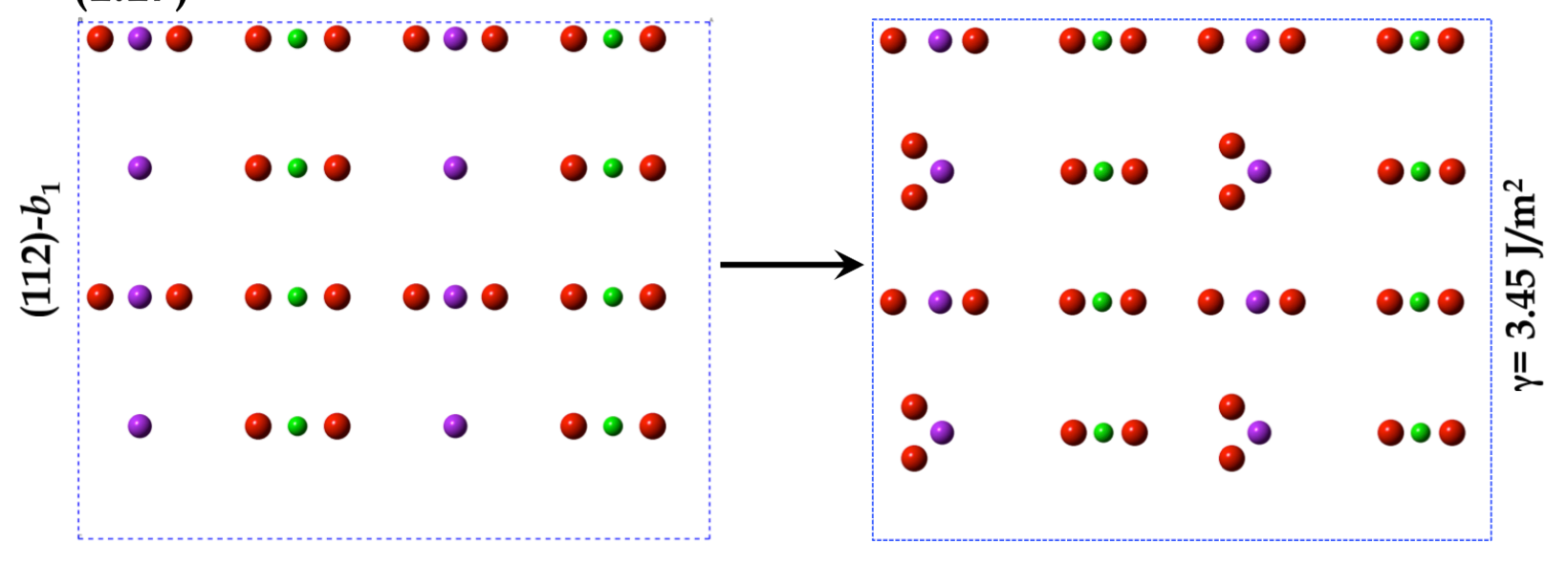




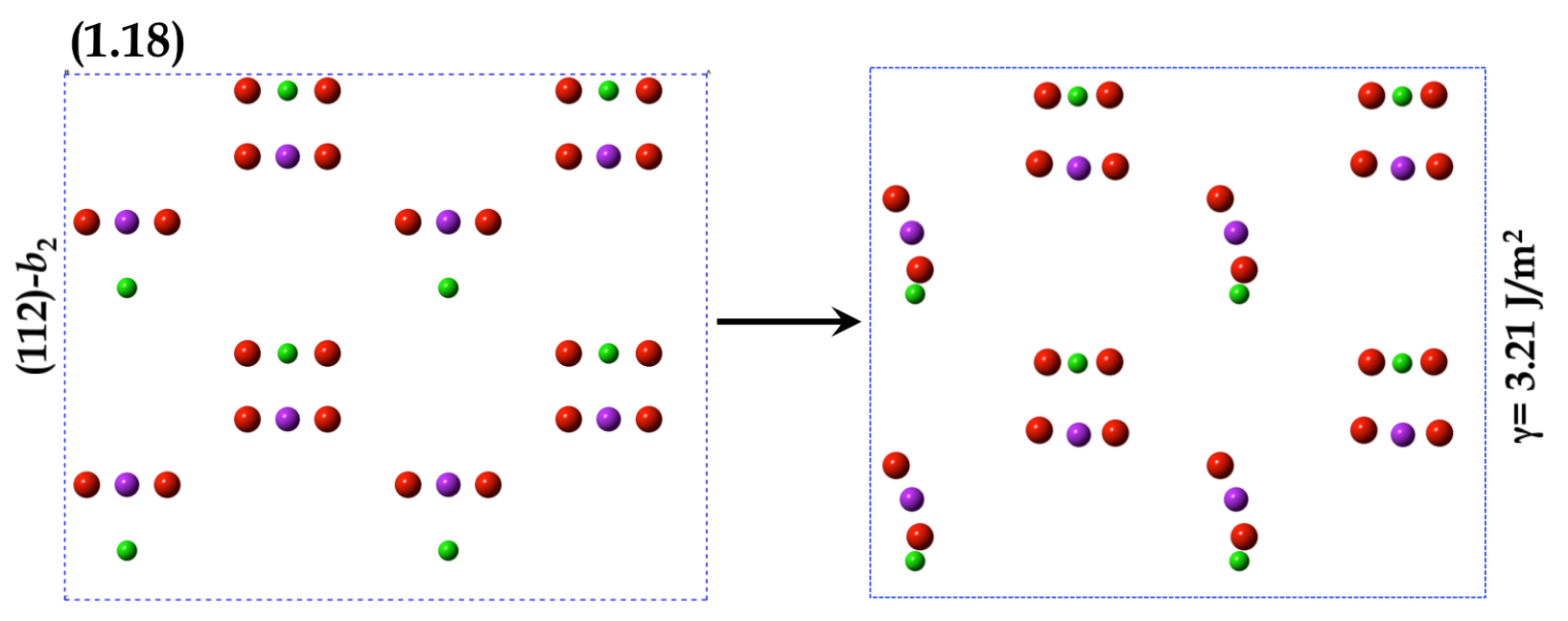

(1.19)

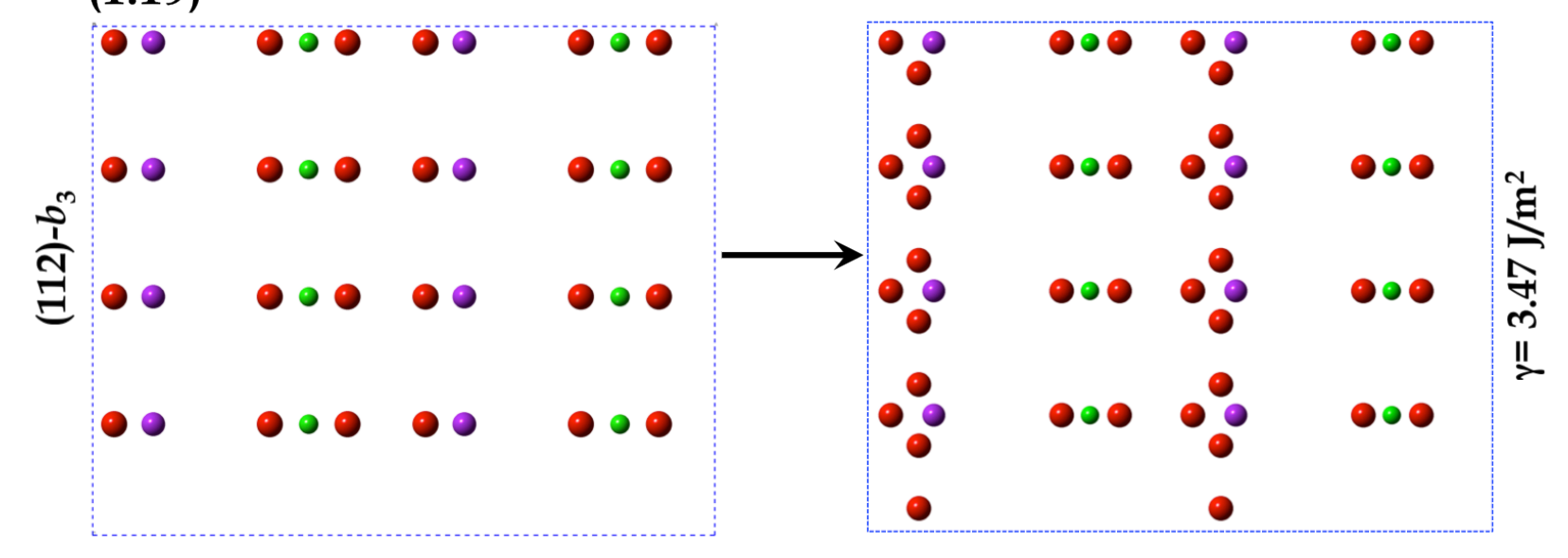

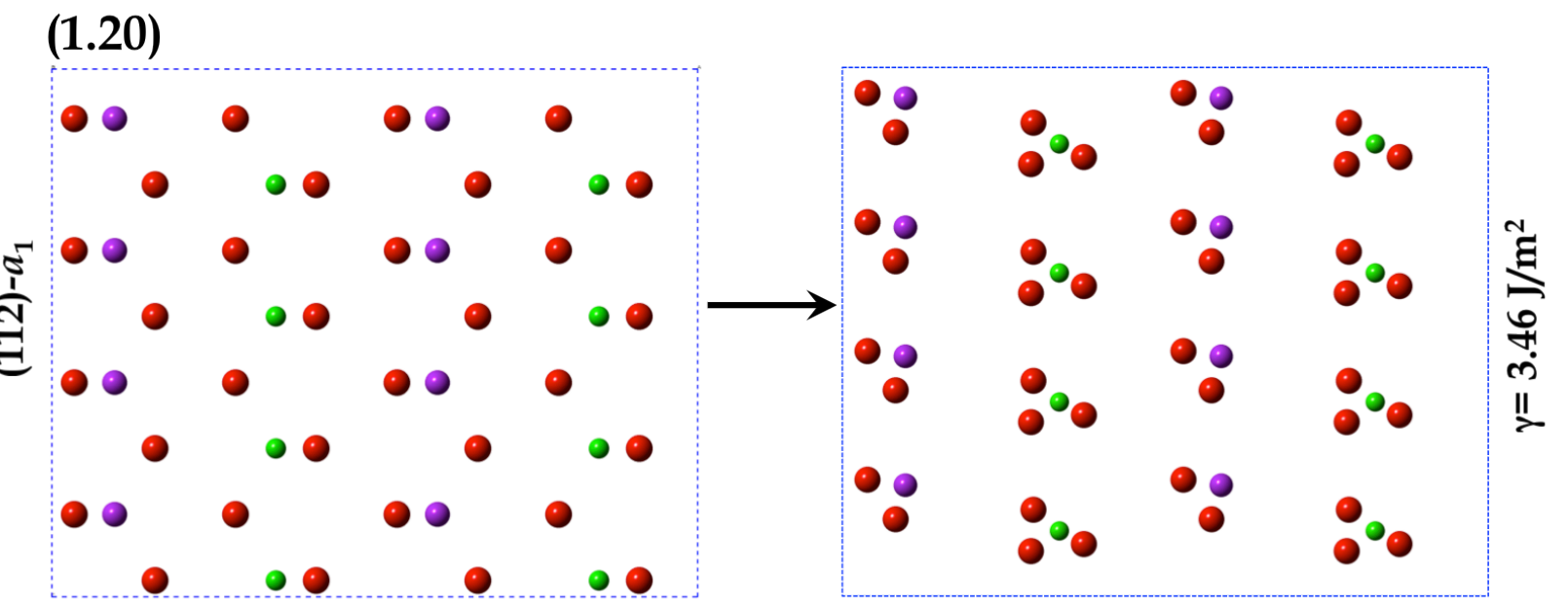




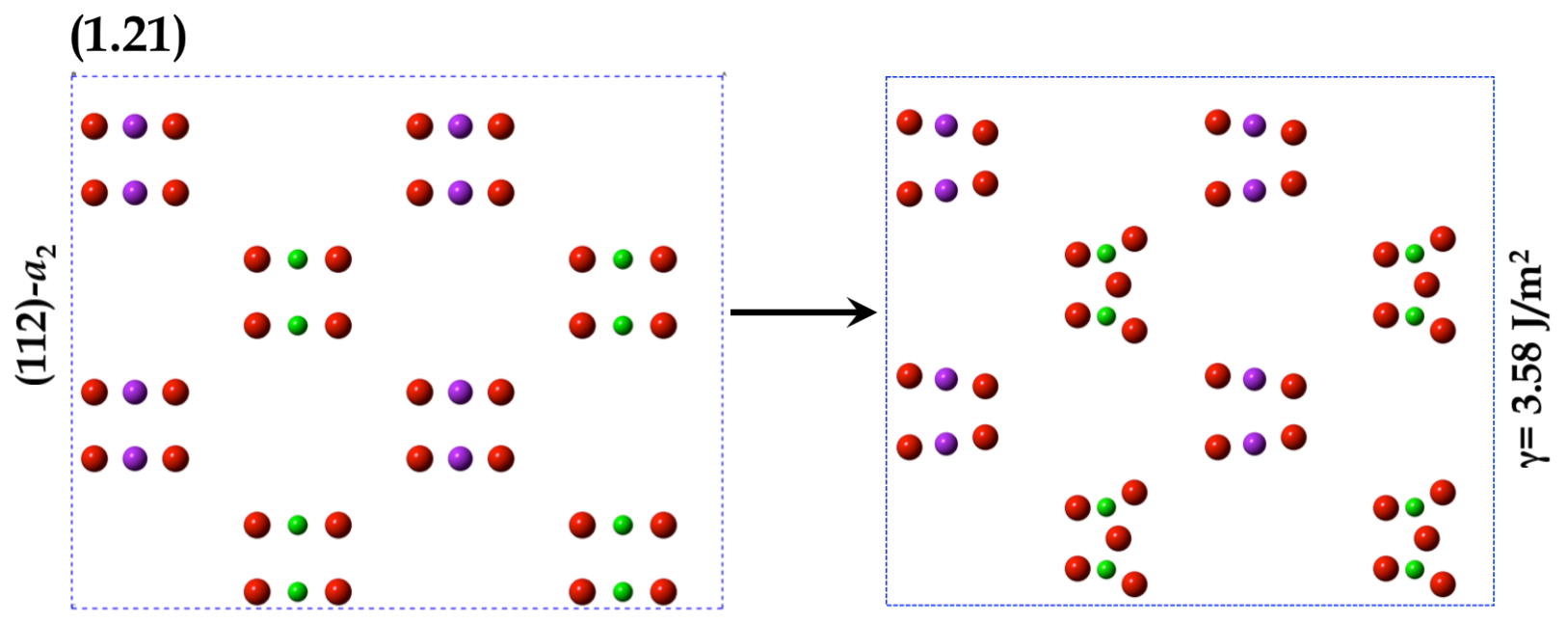

(1.22)

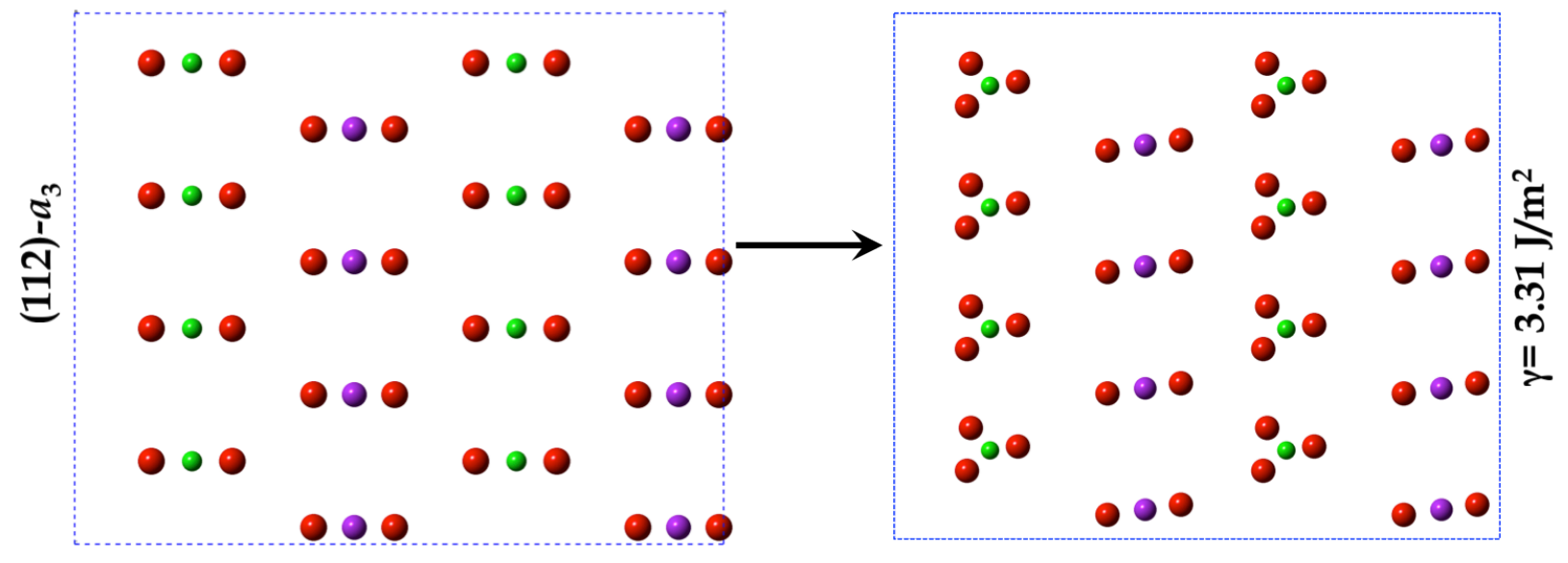


Figure S2. Different annealing schedules for the (110)- $b_{1}$ surface of GTO. The respective annealing temperature $(\mathrm{K})$ is given above every step. The as-built structure of the surface layer is in the upper left (black cell). The color of the dashed surface cell boundary corresponds to the total energy (and line) with the same color after annealing at different temperatures. The view of each structure is along the normal to the surface. Only the surface layer ions are shown for clarity. Color scheme for ions is same as in Figure S1. The different steps in the central figure correspond to the annealing temperature $(K)$ given above the step. At each temperature, the system was allowed to run for $0.3 \mathrm{~ns}$. All the simulations were started from the minimized structure (blue line) with an energy value of $126.22 \mathrm{eV}$ (relative to the lowest energy structure found via the gradual temperature scale), which was obtained by minimizing the as-constructed structure (black cell). For instance, a value of 2000 above the step corresponds to a simulation in which the temperature of the minimized structure (blue cell) is elevated in steps of $500 \mathrm{~K}$ up to $2000 \mathrm{~K}$, and later cooled in steps of $500 \mathrm{~K}$ back to $0 \mathrm{~K}$, and minimized (pink line in this particular instance, with an energy of $0.24 \mathrm{eV}$ ). The reported energies correspond to these final minimized structures and are relative to the lowest energy found via this process, corresponding to $0.0 \mathrm{eV}$ (brown line). In contrast, for the results reported in Figure 5, annealing was performed utilizing a scheme wherein the temperature of the system was initially raised directly to $3000 \mathrm{~K}$ (no gradual ramp up in temperature), and slowly cooled by decreasing the temperature in steps of $500 \mathrm{~K}$. The dashed green line represents this scheme, which has an energy value of $-2.26 \mathrm{eV}$.
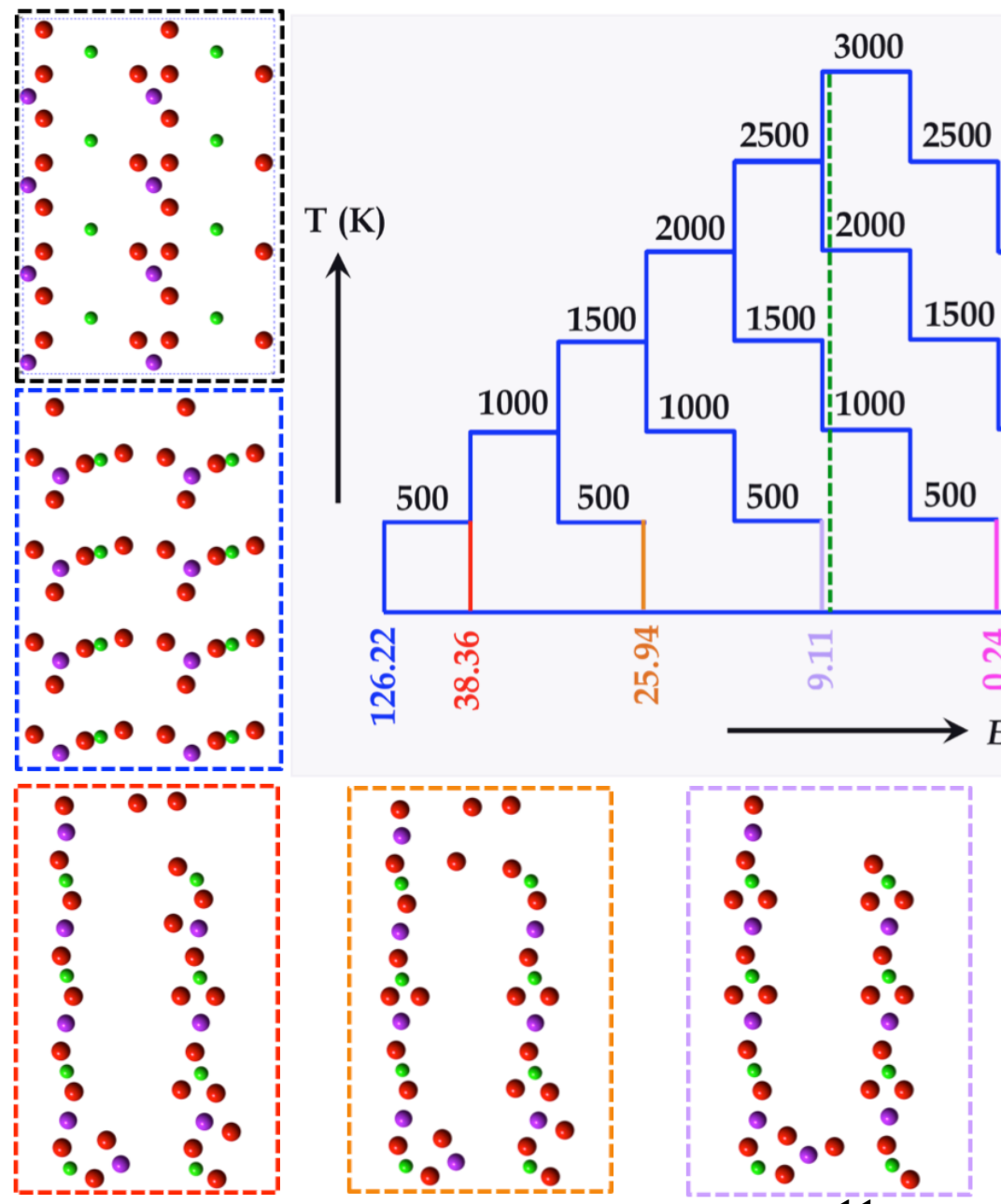
Table S1. Parameterization of the Buckingham potential used in this study. All the parameters are taken from Minervini et al. (Reference 60), except the ones for $\mathrm{Gd}_{2} \mathrm{Hf}_{2} \mathrm{O}_{7}$, which were taken from Stanek et al. (Reference 61)

\begin{tabular}{cccc}
\hline Interaction & $\mathbf{A}(\mathbf{e V})$ & $\boldsymbol{\rho}(\AA)$ & $\mathbf{C}\left(\mathbf{e V} / \AA^{6}\right)$ \\
\hline $\mathrm{O}^{2-}-\mathrm{O}^{2-}$ & 9547.96 & 0.2192 & 32.0 \\
$\mathrm{La}^{3+}-\mathrm{O}^{2-}$ & 2088.89 & 0.3460 & 23.25 \\
$\mathrm{Gd}^{3+}-\mathrm{O}^{2-}$ & 1885.75 & 0.3399 & 20.34 \\
$\mathrm{Lu}^{3+}-\mathrm{O}^{2-}$ & 1618.8 & 0.33849 & 19.27 \\
$\mathrm{Ti}^{4+}-\mathrm{O}^{2-}$ & 2131.04 & 0.3038 & 0.0 \\
$\mathrm{Zr}^{4+}-\mathrm{O}^{2-}$ & 1502.11 & 0.3477 & 5.1 \\
$\mathrm{~Pb}^{4+}-\mathrm{O}^{2-}$ & 1640.34 & 0.3507 & 19.50 \\
$\mathrm{Sn}^{4+}-\mathrm{O}^{2-}$ & 1414.32 & 0.3479 & 13.66 \\
$\mathrm{Mo}^{4+}-\mathrm{O}^{2-}$ & 1223.97 & 0.3470 & 0.0 \\
$\mathrm{Hf}^{4+}-\mathrm{O}^{2-}$ & 1492.60 & 0.3478 & 7.6 \\
\hline
\end{tabular}

